\title{
EuroIntervention
}

\section{The coronary Stent-On-A-Wire (SOAW)}

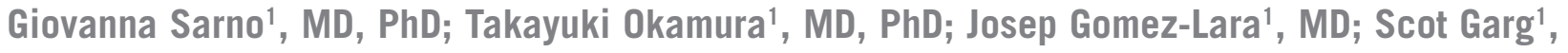 \\ MBChB, MRCP; Chrysafios Girasis ${ }^{1}$, MD; Gregory Kopia², PhD; Mark Pomeranz², MS; \\ William Easterbrook², BSc; Robert-Jan van Geuns, MD, PhD; Wim van der Giessen1, MD, PhD; \\ Patrick W. Serruys ${ }^{1 *}$, MD, PhD
}

1. Thoraxcenter, Erasmus Medical Center, Rotterdam, The Netherlands; 2. Svelte Medical Systems, Inc., New Providence, NJ, USA

Mark Pomeranz and William Easterbrook are employees of Svelte Medical Systems and Gregory Kopia is a consultant to Svelte Medical Systems. All the other authors have no conflict of interest.

\section{Background}

Fixed wire angioplasty systems ${ }^{1,2}$ were introduced in the era of balloon angioplasty as these systems had a lower profile than the bulky, stiff, over-the-wire systems in use at the time. The fixed wire system allowed treatment of more complex lesions. As stenting procedures evolved in the mid 1990s, balloon catheters became mostly relegated to the pre- and post-dilatation of deployed stents which accelerated the use of over-the-wire devices. During this period, stent design and materials had not advanced sufficiently to provide low enough crossing profiles for direct stenting. The need to re-cross a lesion to permit further treatment with a stent and another balloon catheter represented a significant limitation of the fixed-wire balloon system. Reports of wire fractures and difficulties with balloon deflations with one of the manufactures systems (USCI Probe) may also have dampened enthusiasm for these early fixedwire systems. ${ }^{3-5}$ These early limitations of the technology, along with the development of lower profile over-the-wire systems, resulted in the limited use of the fixed-wire balloon catheter in recent years.

The Svelte stent-on-a-wire (SOAW) system represents the next generation of fixed wire technology and is unique in that it has a direct stenting indication by design.

A direct stenting strategy offers the possibility of further reducing the risk of adverse events in high risk percutaneous coronary intervention $(\mathrm{PCl})$ patients, decreasing radiation dose to the operator and patient, and decreasing procedural time and cost. ${ }^{6-10}$

\section{Device description}

The Svelte SOAW System is a high-performance coronary stent delivery system, consisting of a balloon expandable Svelte Stent pre-mounted on the Svelte SOAW single lumen fixed-wire delivery catheter platform (Figure 1). The Svelte Stent is a thin, flexible, bare-metal, L605 cobalt chromium coronary stent. The SOAW delivery catheter has a working length of $145 \mathrm{~cm}$; the device includes a proximal stainless steel shaft with two proximal shaft markers $(90 \mathrm{~cm}$ and $100 \mathrm{~cm}$ ) to indicate the relative position of the delivery system to the end of a brachial or femoral guiding catheter; a flexible distal shaft, a nylon balloon with proximal and distal radiopaque markers located underneath to indicate the working length of the balloon and the expanded stent under fluoroscopy; a spring coil tip, proximal and distal Balloon Control Bands (BCBs) at each end of the balloon to protect leading stent edges from damage during delivery, as well as control balloon expansion and deflation; a standard luer fitting, and an integrated torque device located on the proximal shaft. (Figure 1)

The SOAW System devices are compatible with $5 \mathrm{Fr}$ guide catheters. The $0.74 \mathrm{~mm}(0.029 ")$ profile, leading tip diameter of $0.30 \mathrm{~mm}\left(0.012^{\prime \prime}\right)$, and excellent 1.1:1 torque response allows delivery to distal and tortuous anatomy. The stent reaches nominal size and is deployed at a balloon inflation pressure of 10-11 atm with a rated burst pressure at $18 \mathrm{~atm}$. The SOAW System will be available in 25 models with diameters of $2.5 \mathrm{~mm}, 2.75 \mathrm{~mm}$,

\footnotetext{
* Corresponding author: Ba583a, Thoraxcentre, Erasmus MC, ‘s-Gravendijkwal 230, 3015 CE Rotterdam, The Netherlands

E-mail: p.w.j.c.serruys@erasmusmc.nl
} 


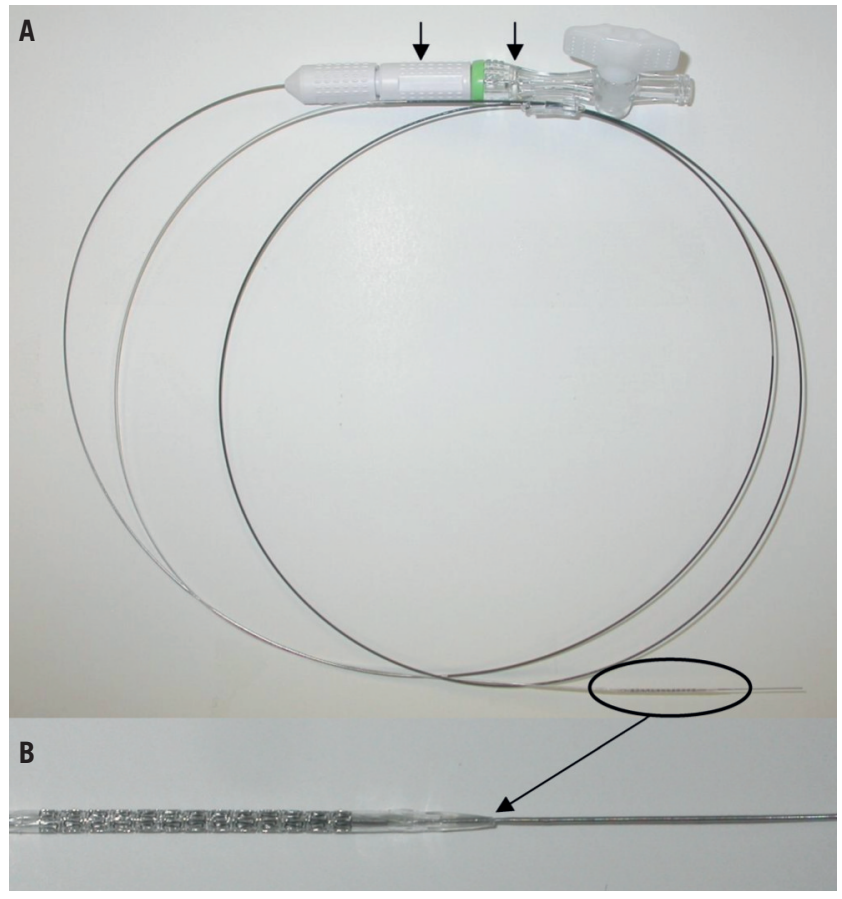

Figure 1. Device description. Panel A shows the whole device system with the proximal shaft of the delivery catheter showing at the end a torquing device and a standard luer fitting (arrows). The stent with the balloon crimped on the wire (circle) are shown in detail in panel $B$.

$3.0 \mathrm{~mm}, 3.5 \mathrm{~mm}$, and $4.0 \mathrm{~mm}$ and lengths of $8 \mathrm{~mm}, 13 \mathrm{~mm}$, $18 \mathrm{~mm}, 23 \mathrm{~mm}$, and $28 \mathrm{~mm}$.

\section{Technical specifications}

Material: L-605 cobalt chromium alloy

Stent lengths: $8 \mathrm{~mm}-28 \mathrm{~mm}$

Balloon diameters: 2.50 to $4.0 \mathrm{~mm}$.

Guide catheter compatibility: $5 \mathrm{Fr}$ (minimum ID 0.056")

Lesion entry profile: $0.30 \mathrm{~mm}\left(0.012^{\prime \prime}\right)$

Crimped stent profile: $0.74 \mathrm{~mm}(0.029 ")$

Working catheter length: $145 \mathrm{~cm}$

Shaft markers: $90 \mathrm{~cm}$ and $100 \mathrm{~cm}$

Balloon: Proximal and distal radio-opaque markers; control bands at each end

Strut thickness: $84 \mu \mathrm{m}$

Length of the wire distal to the stent: $22 \mathrm{~mm}$

\section{Indications for use}

- Elective direct stenting of a single stenotic lesion in a native coronary artery.

- Reference vessel $\geq 2.5 \mathrm{~mm}$ and $\leq 4.0 \mathrm{~mm}$ in diameter.

- Target lesion $<25 \mathrm{~mm}$ in length (the intention should be to cover the entire lesion with one stent of adequate length).

- Target lesion stenosis $\geq 50 \%$ and $<100 \%$.

- Ability to cross the lesion with a wire.

The main exclusion criteria for the use of this device are:

- Target vessel excessively tortuous (two bends $>90^{\circ}$ to reach the target lesion).
- Lesion location that is aorto-ostial or within $5 \mathrm{~mm}$ of the origin of the LAD or LCX.

- Target lesion with side branches $>2.0 \mathrm{~mm}$ in diameter.

- Target lesion severely calcified.

- Target lesions that are likely to prevent complete inflation of an angioplasty balloon or proper placement of the stent or stent delivery system.

\section{Tips and tricks for delivery}

It is important to ensure the system is disconnected from the inflation device as the stent is being tracked through the vessel and across the lesion. If the inflation device is attached, it will negatively impact the torque response of the device as it will act as an anchor when steering into the vessel. Once the stent is in position the inflation device can be attached and the stent can be deployed according to the instructions for use.

It is important to torque the device and get a feel for the torque response when it exits the guiding catheter. Therefore when the wire tip exits the guide, the catheter shaft can be rotated in order to confirm the appropriate rotation of the catheter tip.

If the tip of the device is not rotating one should make sure the torquer is tight on the shaft of the SOAW system. The device can also be rotated at the hub to check the torque control of the tip.

If it is needed to cross the deployed stent with a guidewire, it is best to prolapse the tip of the wire prior to crossing the stent to insure the wire goes through the centre of the stent and not between the struts. When the stent has been fully deployed, it is recommended to push the balloon just distal to the lesion and then make a final angiogram to check result. By doing so, re-crossing the stent if needed with another device is simplified. It is also possible to post-dilate the lesion with the SOAW if required.

\section{Pre-clinical studies and initial clinical experience}

The Svelte SOAW System has been evaluated against the MultiLink Vision (Abbott Vascular, Santa Clara, CA, USA) system in both non-good laboratory practice (GLP) and GLP pre-clinical assessments. These studies relied on porcine models, specifically Yorkshire pigs, with no gender bias. The Svelte SOAW performed equivalently to the MultiLink Vision stent with respect to deliverability and ease of use.

Static $x$-ray images of implanted stents demonstrate the similarity between the Svelte and MultiLink Vision stents, as can be seen in the Figure 2. These images were captured by Svelte Medical Systems, Inc. after the stents were implanted in coronary arteries of porcine models. The imaging system is a Faxitron \#43855B, (Faxitron X-Ray LLC, Lincolnshire, IL, USA) and the images were captured through a $45 \mathrm{~s}$ exposure at $45 \mathrm{kV}$. (Figure 2)

In a recently completed GLP study, eight juvenile Yorkshire swine (30 day cohort) and seven Yucatan mini-swine (90 day cohort) were implanted with either Svelte SOAW or control MultiLink Vision balloon expandable stents. Stented vessels were examined for standard histomorphmometric and histopathologic measures of tissue response. Scanning electron microscopy (SEM) was also conducted to assess endothelialisation. 


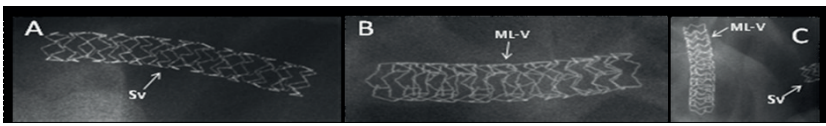

Figure 2. Static $x$-ray images of implanted stents showing the similarity between the Svelte and MultiLink Vision stents. A) $\varnothing 2.5 \mathrm{~mm} 18 \mathrm{~mm}$ long Svelte stent. B) $\varnothing 2.75 \mathrm{~mm} 18 \mathrm{~mm}$ long MultiLink Vision. C) Single image containing a MultiLink Vision stent $(M L-V)$ and a Svelte stent (Sv). The imaging system is a Faxitron \#43855B, the images were captured through a $45 \mathrm{~s}$ exposure at $45 \mathrm{kV}$ after the stents were implanted in coronary arteries of porcine models.

Histopathological assessment demonstrated minimal injury and inflammation at both 30 and 90 days with Svelte SOAW and MultiLink Vision stents. Endothelialisation was complete by 30 days for both stent treatments as was neointimal maturation (Figure 3). Histomorphometry demonstrated no differences between Svelte SOAW and MultiLink Vision stents in neointimal growth, lumen area, percent occlusion, or wall area ratios at either 30 or 90 days post implant (Figure 4). SEM analysis of both stents showed 100\% confluent mixture of polygonal and spindle shaped endothelial cells with minimal inter-cellular spacing at 30 days and cobblestone-like

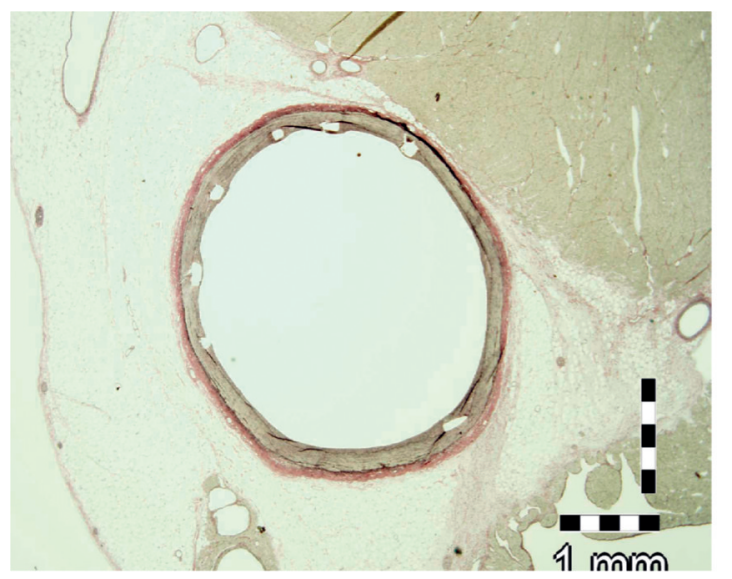

30-Day Mid-RCA with Svelte SOAW

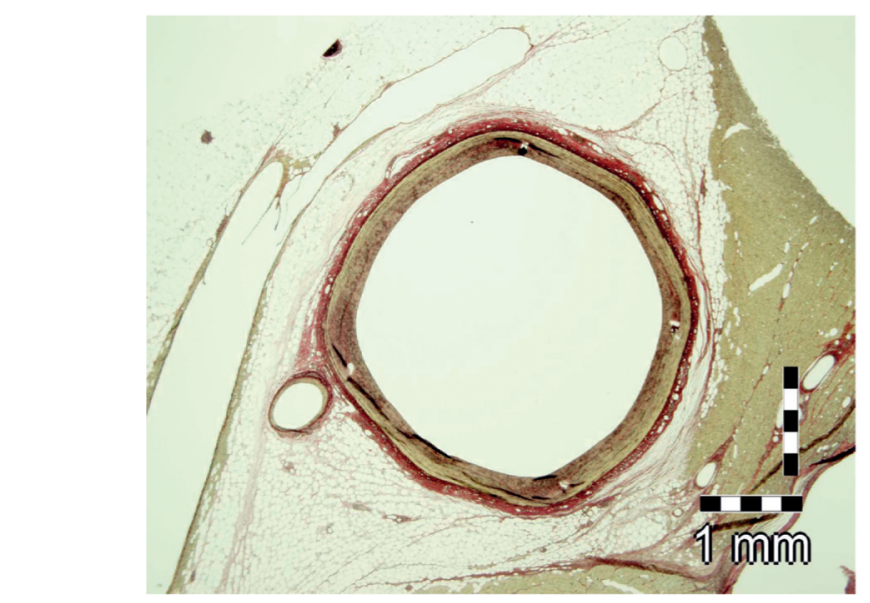

90-Day Mid-RCA with Svelte SOAW

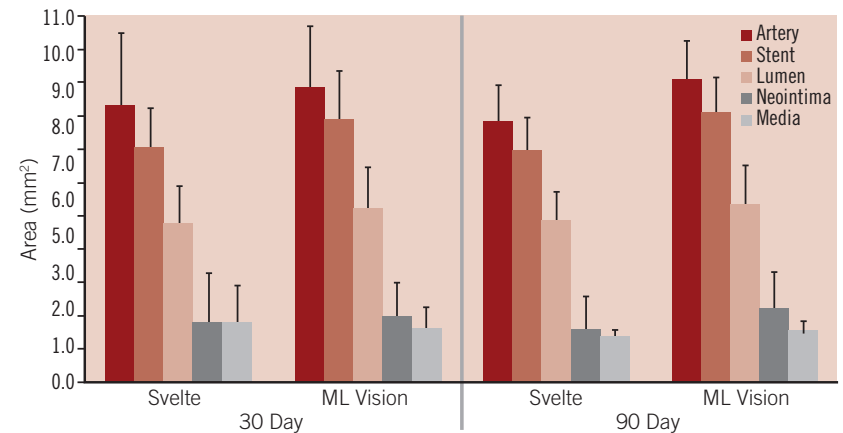

Figure 4. Histomorphic results demonstrating no differences between Svelte SOAW and ML Vision stents in neointimal growth, lumen area, percent occlusion, or wall area ratios at either 30 or 90 days post implant in porcine coronary arteries.

polygonal endothelial cells with tight junctions by 90 days (Figure 5).

Based on the animal studies findings, a prospective, single arm, first-in-man, multicentre study is on going at Thoraxcenter Erasmus MC, Rotterdam, The Netherlands. The first-in-man implantation of the device has recently been performed in a patient with a mid-left
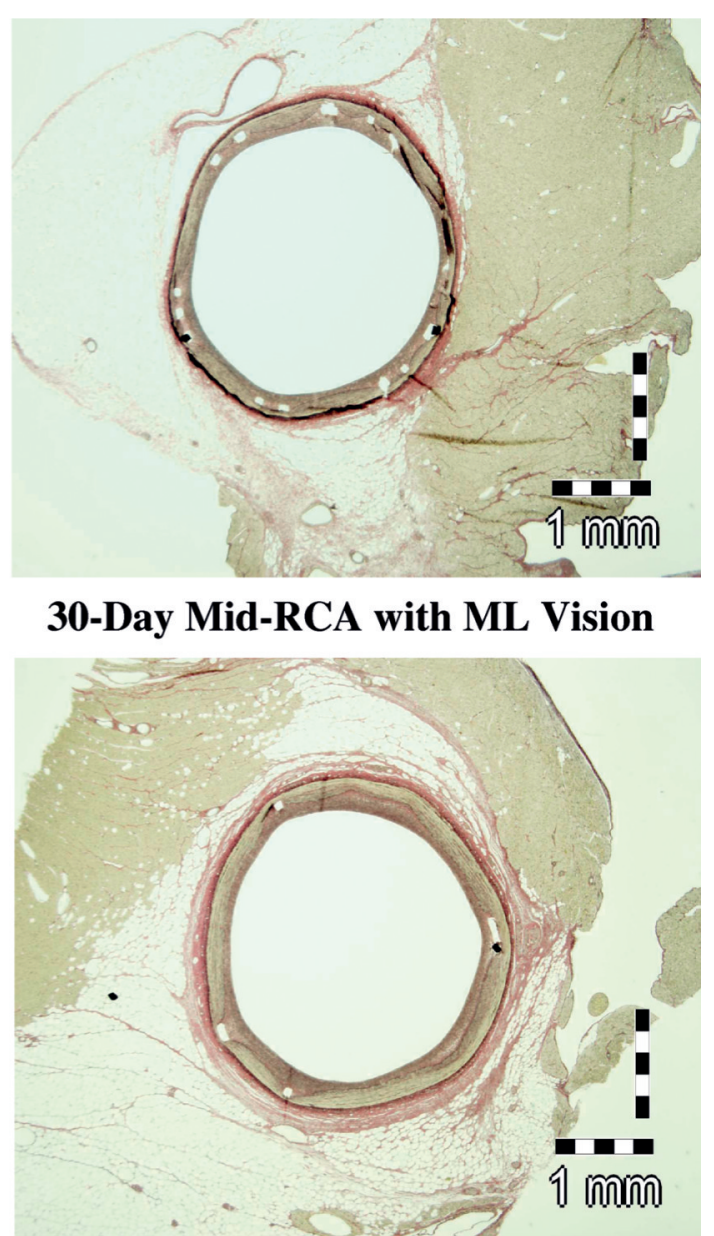

90-Day Mid-RCA with ML Vision

Figure 3. Histopathological images demonstrating minimal injury and inflammation at both 30 and 90 days with Svelte SOAW and ML Vision stents. RCA, right coronary artery. 


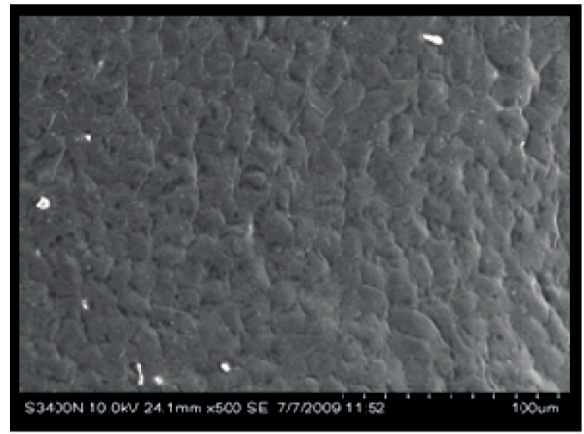

30-Day Svelte SOAW

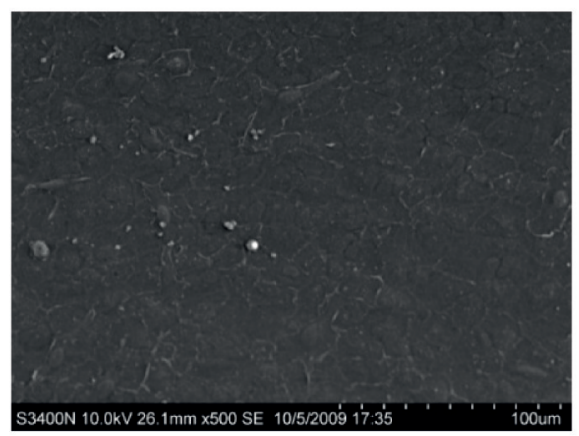

90-Day Svelte SOAW

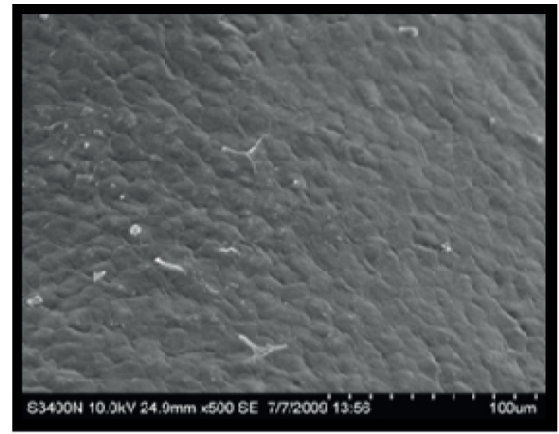

30-Day ML Vision

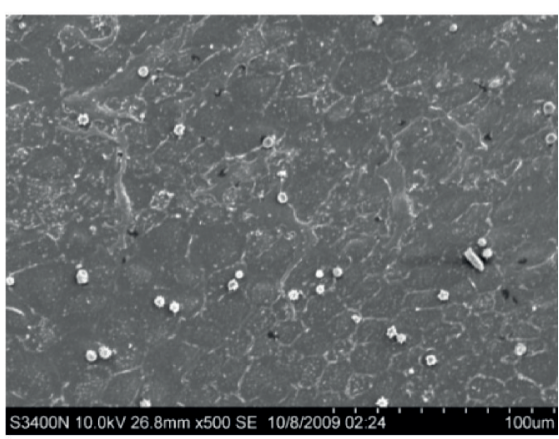

90-Day ML Vision

Figure 5. Scanning electron microscopy (SEM) of vessels implanted with either Svelte SOAW or ML Vision stents showing 100\% confluent mixture of polygonal and spindle shaped endothelial cells with minimal inter-cellular spacing at 30 days and cobblestone-like polygonal endothelial cells with tight junctions by 90 days.

circumflex coronary artery lesion. The 3-D quantitative coronary angiogram (QCA) pre- and post-stenting, and the 3-D optical coherence tomography (OCT) post-stenting are shown in Figure 6 (A, B) and Figure 7. The 3-D angiographic reconstruction with virtual navigation through the centreline of the vessel and the coronary angiogram showing the positioning of the device through the lesion is displayed on www.eurointervention.com.

\section{Conclusions}

The Svelte SOAW system represents the next generation iteration of fixed wire technology, and is unique in that it has a direct stenting indication by design.

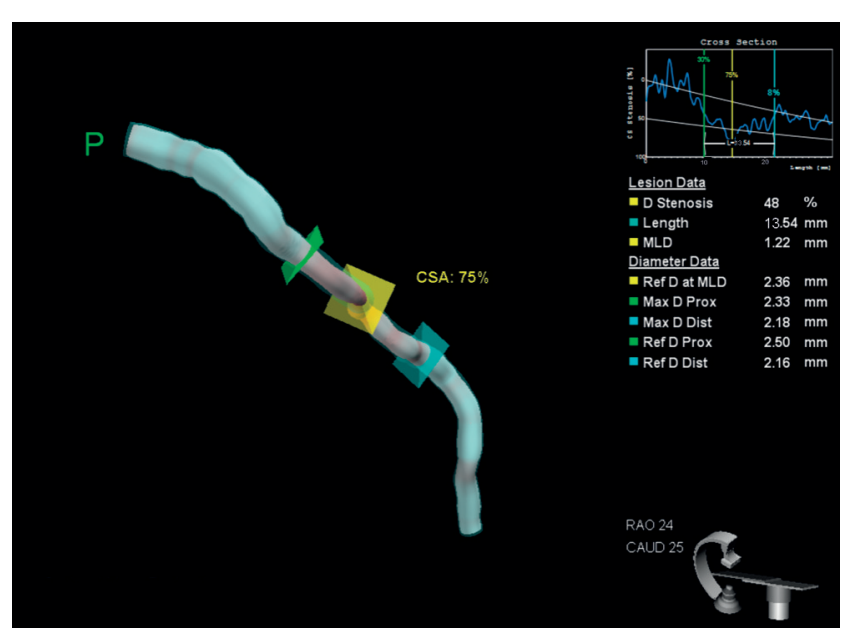

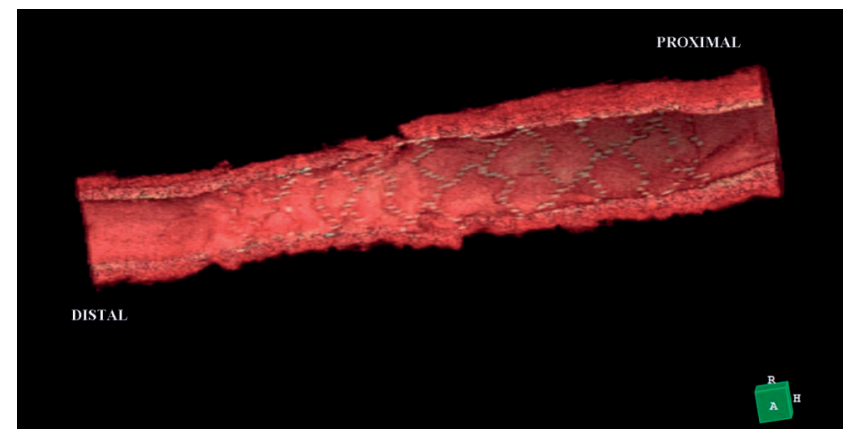

Figure 7. 3-D optical coherence tomography (OCT) post-stenting showing well apposed Svelte stent struts.

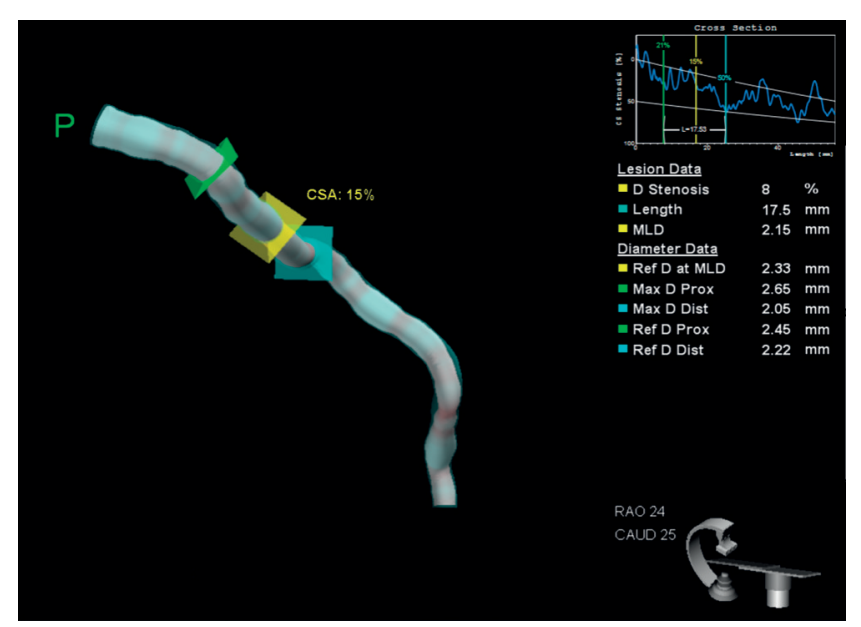

Figure 6. A) 3-D quantitative coronary angiogram, QCA pre-stenting. B) 3-D QCA post-stenting. 
It may enable a further reduction in procedure time, contrast use and cost compared to conventional devices.

Results from a GLP study demonstrate an acceptable healing response when the Svelte SOAW is implanted in porcine coronary arteries with complete endothelialisation by 30 days that was no different than that observed with the MultiLink Vision stent.

The potential downsizing of sheath sizes and improved outcomes with direct stenting may make this approach appealing.

\section{References}

1. O'Neill BJ, Feldman RL, Palmer SL, Creighton J, Fitzgerald N, Foster CJ, Teskey RJ, Kells CM, Corbett BN, Macdonald RG. Comparison of fixed-wire and over-the-wire balloon dilatation systems for percutaneous transluminal coronary angioplasty. Am J Cardiol 1994; 73:113-116.

2. Thomas ES, Williams DO, Neiderman AL, Douglas JS, King SB, 3rd. Efficacy of a new angioplasty catheter for severely narrowed coronary lesions. J Am Coll Cardiol 1988; 12:694-702.

3. Feldman RL, Trice WA, Hennemann WW, 3rd, Furst A. Retrieval of a fractured USCI probe tip from a diseased coronary artery using another fixed-wire balloon catheter, the Cordis Orion. Cathet Cardiovasc Diagn 1990; 19:257-263.

4. Hamada Y, Matsuda Y, Takashiba K, Ohno H, Fujii B, Ebihara H, Hyakuna E. Difficult deflation of Probe balloon due to twisting the system. Cathet Cardiovasc Diagn 1989; 18:12-14.
5. van den Brand M, de Feyter P, Serruys P, Zijlstra F, Bos E. Fracture of a balloon on a wire device during coronary angioplasty. Cathet Cardiovasc Diagn 1989; 16:253-257.

6. Hamon M, Richardeau Y, Lecluse E, Saloux E, Sabatier R, Agostini D, Filmont JE, Grollier G, Potier JC. Direct coronary stenting without balloon predilation in acute coronary syndromes. Am Heart J 1999; 138(1 Pt 1):55-59.

7. Pentousis D, Guerin Y, Funck F, Zheng H, Toussaint M, Corcos T, Favereau $X$. Direct stent implantation without predilatation using the MultiLink stent. Am J Cardiol 1998; 82:1437-1440.

8. Wilson SH, Berger PB, Mathew V, Bell MR, Garratt KN, Rihal CS, Bresnahan JF, Grill DE, Melby S, Holmes DR, Jr. Immediate and late outcomes after direct stent implantation without balloon predilation. J Am Coll Cardiol 2000; 35:937-943.

9. Briguori C, Sheiban I, De Gregorio J, Anzuini A, Montorfano M, Pagnotta P, Marsico F, Leonardo F, Di Mario C, Colombo A. Direct coronary stenting without predilation. J Am Coll Cardiol 1999; 34:19101915.

10. Serruys PW, S IJ, Hout B, Vermeersch P, Bramucci E, Legrand V, Pieper M, Antoniucci D, Gomes RS, Macaya C, Boekstegers P, Lindeboom W. Direct stenting with the Bx VELOCITY balloon-expandable stent mounted on the Raptor rapid exchange delivery system versus predilatation in a European randomized Trial: the VELVET trial. Int $J$ Cardiovasc Intervent 2003; 5:17-26. 